\title{
A variação lexical no campo semântico dos acessórios do Projeto Atlas Linguístico do Brasil
}

\author{
The lexical variation in the semantic field of the accessories of the Atlas \\ Linguistic Project of Brazil \\ Carina Sampaio Nascimento ${ }^{1}$ \\ Faculdade Batista da Bahia \\ Marcela Moura Torres Paim ${ }^{2}$ \\ Universidade Federal Rural de Pernambuco
}

\begin{abstract}
- RESUMO: Este artigo visa a investigar o léxico nos inquéritos do Projeto Atlas Linguístico do Brasil, $\mathrm{ALiB}$, e busca analisar os itens lexicais relativos ao campo semântico dos acessórios, presentes no repertório linguístico de informantes da faixa I (18-30 anos) e da faixa II (50-65 anos). Este estudo, que se centra nas capitais e interiores do Nordeste e do Sul, será realizado na perspectiva da Dialetologia, buscando verificar as variações diatópicas. Pretende-se investigar o léxico referente ao campo dos acessórios, buscando apresentar os condicionamentos socioculturais que atuam na variação semântico-lexical. No universo selecionado no que se refere às regiões Nordeste e Sul do país, com o total de 122 pontos, foram registradas dez denominações para a questão referente à pergunta 192, "como se chama um objeto fino de metal, para prender o cabelo?”. Dessa forma, o resultado deste estudo possibilita a verificação de uma realidade espacial, mostrando diferenças e semelhanças nas regiões brasileiras.
\end{abstract}

- PALAVRAS-CHAVE: Variação. Léxico. Dialetologia. Acessórios.

- ABSTRACT: This paper aims to investigate the lexicon in the surveys of the Linguistic Atlas of Brazil Project, ALiB, and seeks to analyze the lexical items of the questionnaire related to the semantic field of the accessories, present in the linguistic repertoire of informants in age group I (18-30 years) and in age group II (50-65) years). This study, which focuses on the capitals and interiors of the Northeast and South, will be carried out from the perspective of Dialectology, seeking to verify diatopic. It is intended to investigate the lexicon referring to the semantic field of the clothing, seeking to present the socio-cultural conditions that operate in the semantic-lexical variation. In the universe selected with regard to the Northeast and the South region, with a total of 122 points, ten denominations were registered for the question referring to question 192, "what is a thin metal object called, to hold the hair?" Thus, the result of this study enables the verification of a spatial reality, showing differences and similarities in the Brazilian regions.

- KEYWORDS: Variation. Lexicon. Dialectology. Acccessories.

\footnotetext{
1 Possui Mestrado e realiza o Doutorado pelo Programa de Pós-Graduação em Língua e Cultura da Universidade Federal da Bahia. Atua como Professora de Língua Portuguesa da Faculdade Batista da Bahia. Email: carinasampaionascimento@gmail.com

2 Possui Pós-doutorado em Linguística pela Universidade Estadual de Feira de Santana. Atua como Professora de Língua Portuguesa do Departamento de Letras da Universidade Federal Rural de Pernambuco e do Programa de Pós-Graduação em Língua e Cultura da Universidade Federal da Bahia. E-mail: marcela.paim@ufrpe.br
} 


\section{Introdução}

O estudo sobre o léxico vem contribuindo com as pesquisas na área da Dialetologia, pois oferece o registro da diversidade lexical de uma comunidade e expressa designações que o indivíduo atribui para nomear a realidade de seu mundo. Nesse sentido, as investigações da geolinguística do português falado no Brasil têm se dedicado para alcançar o objetivo central do Atlas Linguístico do Brasil (ALiB), no que se refere à realização da descrição da realidade linguística do Brasil tendo em vista a pluridimensionalidade.

Este estudo está pautado nos princípios da Dialetologia; essa área de pesquisa se torna, de início, a ciência da variação espacial, que, segundo Coseriu (1982), se dedica à delimitação dos espaços e o reconhecimento de áreas, contribuindo para uma visão de dialeto desprovida de estigmatização.

A identificação dessa distribuição espacial das variantes linguísticas permite um conhecimento sobre a trajetória do fenômeno da variação em função dos espaços geográficos, podendo-se identificar áreas linguísticas bastante definidas, cujas características podem fornecer elementos importantes para a compreensão das particularidades da fala nos mais diferentes ambientes espaciais, sociais, culturais. Assim, as realizações lexicais presentes nas falas podem expressar sua visão de mundo, suas crenças, suas ideologias, seus valores e a norma linguística aprendida através das práticas socioculturais presentes em seu grupo social, que, geralmente, mantêm entre si uma identidade linguística.

Este artigo foi realizado na perspectiva da Dialetologia, buscando verificar as variações diatópicas. Dessa forma, foi investigado o léxico referente ao campo dos acessórios, buscando apresentar os condicionamentos linguísticos e sócio-históricoculturais que atuam na variação semântico-lexical em relação às respostas da questão 192 "Como se chama um objeto fino de metal, para prender o cabelo? Mostrar grampo (com pressão) /ramona/ misse", nas capitais e municípios das regiões Nordeste e Sul do Brasil (COMITÊ NACIONAL DO PROJETO ALiB, 2001, p. 37). Pretende-se, a partir da observação e análise dos dados, compreender os aspectos sociais, culturais e históricos que se relacionam com as realizações lexicais.

As motivações desta pesquisa surgem devido à produtividade lexical observada em exemplos de lexias trazidas pelos sujeitos da pesquisa para designar o objeto, comumente, conhecido ou designado como grampo, revelando uma forma de expressão de uma época, de tendências de moda, que podem ajudar a entender o homem e a mulher e a sua relação com a sociedade, pois o traje e o acessório revelam uma identidade de um indivíduo e de uma civilização e carregam traços de uma geração nas suas vestimentas, adereços e produtos. Segundo Lipovetsky (2009, p. 24-25), "[...] a moda é formação essencialmente sócio-histórica, circunscrita a um tipo de sociedade".

Nesse sentido, o objetivo desse estudo é mapear parte da realidade linguística brasileira, com base no corpus referente ao léxico do campo dos acessórios do Projeto $\mathrm{ALiB}$, pautada na Geolinguística pluridimensional, referente às denominações utilizadas para "objeto fino de metal que serve para prender o cabelo", levando em consideração a rede de pontos do Nordeste e Sul do Brasil.

\section{A variação lexical dos adornos de cabelo}

Os estudos sobre a variação lexical no Brasil têm crescido à medida que se torna emergente explicar determinados usos linguísticos, que comprometem a inteligibilidade entre os próprios falantes de uma determinada língua e de aprendizes desta língua como 
língua estrangeira ou segunda língua. Isso acontece, porque determinados usos linguísticos são construídos com seus usuários e se solidificam a partir dos usos, dos contextos em que estão inseridos.

Os acessórios de cabeça, tanto masculinos quanto femininos, carregam registro de um povo, de uma época e que vão refletir a posição social, de quem os usa, sua funcionalidade e sua cultura. As civilizações antigas costumavam ter uma atenção para um adorno na cabeça, como: chapéus ou algum tipo de acessório.

No entanto, nem sempre o clima de uma região determinava o uso de determinada roupa ou adorno. Desde os primórdios, quando grandes civilizações antigas surgiram nos vales férteis do Eufrates, do Nilo e do Indo, em regiões tropicais, onde a proteção contra o frio não pode ter sido o maior motivo para se usar roupas, acredita-se, como base na Gênesis, de que o uso de roupas se deveu ao pudor, até a noção sofisticada de que eram usados por intenção de exibição e de mágica protetora (LAVER, 1989).

Os adornos de cabeça, sempre, estiveram presentes na indumentária do povo, no material histórico mostra a lei assíria, 1200 a.C., que impunha as mulheres casadas a usarem véus todas as vezes em que estivessem em público. $\mathrm{O}$ que traz até século passado esse costume em algumas comunidades. $\mathrm{O}$ acessório masculino, nessa época, tinha forma de um vaso invertido, mas também usavam os chamados elmos, usados para proteção craniana (LAVER, 1989).

Conforme Cosgrave (2012, p. 37), há indícios de que o uso dos chapéus se iniciou na Creta Minoica; para a pesquisadora, nenhum dado mostra a origem do chapéu, no entanto pelo fato de Creta ser concebida como primeira civilização europeia, com início em 3000 a.C. até 1450 a.C., encontram-se indícios deste complemento do vestuário por volta de 2000 a.C.. Segundo Laver (1989, p. 23), os homens cretenses não usavam nada na cabeça, apesar de levarem gorro em algumas ocasiões, já os adornos das mulheres eram mais elaborados e de várias formas. Grandes quantidades de joias foram encontradas nas tumbas de homens e mulheres cretenses: anéis, braceletes, grampos de cabelo.

Existia uma variedade muito grande nos adornos cretenses, no entanto, o mesmo não acontecia com a civilização egípcia antiga, a qual possuía outros padrões de higiene, sendo assim os homens raspavam a cabeça e colocavam um acessório quadrado produzido por um tecido listrado; em cerimonias, eles utilizavam perucas. As mulheres jovens, também, raspavam as cabeças, mas as mais velhas deixavam longos os cabelos (LAVER,1989).

É importante notar que, antes dos triunfos dos gregos sobre os persas, os penteados de homens e mulheres eram com cabelos soltos e compridos, posteriormente, esse uso passou só para meninos e mulheres, quando chegava na puberdade os meninos cortavam os cabelos e ofereciam aos deuses.

Em relação aos penteados das gregas, elas colocavam sobre a cabeça panos e fitas amarrados; além disso, era comum o uso de uma espécie de tiara muito popular denominada stephanie. Como expõe Laver (1989, p. 29), "as mulheres ricas usavam tiaras de ouro e pedras preciosas". Até os dias atuais, recebemos influências dos acessórios gregos, isso é caracterizado a partir dos lenços envoltos à cabeça, bem como nas tiaras com pedras, normalmente, utilizadas em cerimônias festivas.

Desde a Antiguidade, os cabelos e os penteados são uma expressão de status social, idade, gênero e crenças. Pode-se afirmar que, ao longo da história, os adornos serviram de instrumento para o indivíduo se diferenciar do outro, principalmente por meio do penteado.

A partir da década de 1760 , do século $\mathrm{XX}$, os penteados começam a serem produzidos de forma diferente, na época da fontange, os cabelos eram presos de forma 
baixa, posteriormente, os penteados se elevam e ganham notoriedade nos anos de 1770 . Conforme descreve Laver (1989), o penteado da época era:

Um topete altíssimo puxado a partir da raiz dos cabelos e esticado sobre uma almofada no alto da cabeça formava um centro de construção; fileiras de cachos dos lados; um chinó dependurado atrás defendia seu occipício como um contraforte; e toda a estrutura era mantida no lugar e à prova d'água por um grande número de longos alfinetes simples e duplos (LAVER, 1989, p. 140, grifo nosso).

Os denominados "alfinetes duplos" é o que chamamos de "grampos de cabelo", os quais entram no novo estilo da corte francesa junto com a "almofada" uma espécie de travesseirinho de fibra, lã ou crina de cavalo e, como causava dores de cabeça, pelo peso, o arame ganhou um substituto para prender o cabelo, mas o "alfinete duplo" continua nos penteados das mulheres francesas até a atualidade (LAVER, 1989).

Os grampos se popularizam, em meados de 1900, do século XX, mas não sofrem grandes mudanças no seu formato. Foram produzidos, inicialmente, em formato parecido com o de espinha de animal e espinho de plantas e para a confecção eram utilizados em diversos materiais, tais como: marfim, bronze e madeira entalhada. As civilizações antigas soterradas da Ásia produziram muitos grampos de cabelo de osso, ferro, bronze, prata e ouro. Eram produzidos com formato achatados, alguns decorados, mas todos eles mostram que a forma do grampo continuou a mesma por 10000 anos.

Segundo Lima et al. (2016), com o tempo, o acessório foi modificando a sua estrutura para forma de " $u$ ". No século XIX, começou a ser produzido em grande escala e com tons diferentes e adornos presentes, tornando-se item indispensável na produção de penteados e versatilidade para prender o cabelo, não mais para esconder, mas, para pôr em relevo, passou a receber customização com pedras, contas e objetos diversos, modificando o objetivo do uso que a consumidora tem em relação ao item.

\section{Procedimentos metodológicos}

O estudo foi desenvolvido a partir dos dados do Projeto ALiB - Atlas Linguístico do Brasil, o qual possui sede na Universidade Federal da Bahia - UFBA. A rede de pontos do ALiB é constituída por 250 pontos, seguindo critérios demográficos, históricos e culturais, cujos dados foram coletados in loco, por uma equipe composta de cerca de 30 inquiridores, selecionados pelo Comitê Nacional do Projeto.

Os questionários linguísticos foram utilizados como instrumento de coleta de dados por membros do Comitê Nacional e demais inquiridores, levando-se em conta, na sua elaboração, os questionários dos atlas regionais já publicados, bem como o Atlas Linguístico-Etnográfico de Portugal e Galiza. Apresenta-se composto pelo Questionário Fonético-Fonológico (QFF), Questionário Semântico-Lexical (QSL) e Questionário Morfossintático (QMS), acrescentando-se questões referentes à pragmática, temas para discursos semidirigidos, questões metalinguísticas e texto para leitura.

Analisamos a pergunta 192 pertencente ao campo semântico dos acessórios do Questionário Semântico Lexical - QSL, que consta no Questionário ALiB 2001 (COMITÊ NACIONAL DO PROJETO ALiB, 2001, p. 37).

Foram escutados os registros das gravações de 536 informantes das localidades das regiões Nordeste e Sul organizados por faixa etária, sexo e escolaridade, variáveis sociais controladas pelo ALiB da seguinte maneira:

a. faixa etária: a faixa I agrega informantes cuja idade se encontra entre $18 \mathrm{e}$ 30 anos, ao passo que a faixa II incorpora sujeitos entre 50 e 65 anos; 
b. sexo: consideram-se homens e mulheres;

c. escolaridade: há quatro indivíduos de nível universitário (somente para as capitais) e quatro indivíduos de nível fundamental incompleto nas demais localidades incluindo as capitais. Ou seja, capitais com 8 informantes e demais localidades com 4 informantes.

No que se refere à rede de pontos, as análises dos dados foram realizadas a partir das respostas cedidas pelos informantes entrevistados nos 122 pontos linguísticos das correspondentes regiões, no total de 536 informantes, 348 da região Nordeste e 188 da região Sul.

Foi realizada a análise de 14 formas lexicais válidas, para a pergunta 192 do questionário semântico-lexical, referentes as duas regiões estudadas.

Sobre as abstenções, foram 95 exclusões para a questão 192. É importante pôr em relevo outros critérios estabelecidos para a constituição e a organização dos dados:

a) As formas lexicais: broche, bico de pato e clipes não foram consideradas válidas se referindo à resposta 192, e o mesmo ocorre para as formas lexicais: clipe, mola, xuxa, colar, gancho.

b) As variantes fônicas, como: berilo/birilo, biliro/ miss/misse; presilha/prisilha, friso/frise, foram agrupadas, mas não foi realizada, para este artigo, a discussão sobre aspectos da variação fonética.

c) Foram agrupadas as formas lexicais para a resposta à pergunta 192: grampo/grampo de cabelo/grampinho/guarampo/grampinha de cabelo; pregador/pregador de cabelo; prendedor e prendedor de cabelo.

d) Para a categoria outros foram agrupados os itens lexicais de menos ocorrências (pregador, pegador e cigarra, com uma ou duas ocorrências cada).

A pesquisa foi pautada no método qualitativo e quantitativo, levando em conta aspectos os quais visam a observar o falante em suas relações sociais, verificando-se a variação lexical, seguindo os pressupostos teórico-metodológicos da Dialetologia.

\section{Análise dos dados}

O total corresponde a 522 dados para a questão 192 "como se chama um objeto fino de metal, para prender o cabelo?", 341 para região Nordeste e 181 para região Sul, com base no questionário semântico-lexical (QSL) do campo dos acessórios do Projeto Atlas Linguístico do Brasil (COMITÊ NACIONAL DO PROJETO ALiB, 2001, p. 37).

Questão esta formulada e testada pelos pesquisadores do ALiB e produzida com caráter onomasiológico, isto é, pesquisa semântica das designações, quando usa o conceito para verificar os signos correspondentes.

Sendo assim, apresentaremos, nesta seção, os dados, por meio de quadros, tabelas, gráficos, cartas linguísticas, analisados na perspectiva semântico-lexical e geolinguística, levando em conta as dimensões geográficas da língua.

Esta seção está dividida a partir do estudo em dicionários de língua portuguesa, relacionando com exemplos de trechos de inquéritos linguísticos e a análise geolinguística dos dados.

4.1 Análise léxico-semântica para "um objeto fino de metal, que serve para prender o cabelo" 
Foram registradas as seguintes designações referentes às respostas coletadas para a pergunta 192 "como se chama um objeto fino de metal, para prender o cabelo?" para a região Nordeste e a região Sul do Brasil: misse, grampo (de cabelo)/ grampinha/ guarampo, presilha, birilo, friso, fivela, pegador, pregador (de cabelo), prendedor (de cabelo), cigarra, ramona, joaninha, ladona, passador, bico de pato, broche, clipes.

Considerou-se, após análise das respostas, o registro total de 14 válidas, a saber: misse, grampo (de cabelo)/grampinha/guarampo, presilha, birilo, friso, fivela, pegador, pregador (de cabelo), prendedor (de cabelo), cigarra, ramona, joaninha, ladona e passador, portanto bico de pato, broche e clipes são vocábulos não validados. É importante mencionar que os agrupamentos feitos com grampo (de cabelo), pregador (de cabelo) e prendedor (de cabelo) ${ }^{3}$ foram motivados pelo fato de (de cabelo), embora presente na fala dos informantes, existir, também, na pergunta, configurando-se como um caso de repetição do enunciado.

Buscou-se entender de que modo estavam dicionarizadas as formas lexicais mais produtivas e observar o significado atribuído aos itens lexicais coletados. Sendo assim, foram consultados quatro dicionários de língua portuguesa, como: Moares Silva (1789, 2018), Ferreira (1999), Aulete (2014) e Houaiss (2015).

Os itens lexicais mais recorrentes das duas regiões, Nordeste e Sul, estão organizados no quadro 1 que apresenta a seguinte legenda: D (dicionarizado), DOA (dicionarizado com outra acepção) e ND (não dicionarizado).

Quadro 1: Dicionarização dos léxicos mais produtivos para "objeto fino de metal, para prender o cabelo"

\begin{tabular}{|l|c|c|c|c|}
\hline \multicolumn{1}{|c|}{ Denominações } & \multicolumn{3}{|c|}{ Dicionários consultados } \\
\hline & Moraes Silva (1789, 2018) & Ferreira (1999) & Aulete (2014) & Houaiss (2015) \\
\hline Misse & ND & ND & DOA & DOA \\
\hline Grampo (de cabelo) & ND & D & DOA & D \\
\hline Presilha & D & D & D & D \\
\hline Birilo & DOA & DOA & DOA & DOA \\
\hline Friso & DOA & DOA & D & DOA \\
\hline Ramona & ND & ND & D & D \\
\hline
\end{tabular}

Fonte: autoria própria.

$\mathrm{D}=$ Dicionarizada;

$\mathrm{ND}=$ Não dicionarizada;

DOA= Dicionarizada com outra acepção.

Pesquisar os itens lexicais nos dicionários é de grande relevância, pois estes servem de instrumentos de prescrição dos verbetes, trazendo, assim, informações necessárias para o estudo da palavra. No entanto, os dicionários gerais da língua não dão conta da dinamicidade e elasticidade da língua, não necessariamente recobrem o léxico

\footnotetext{
${ }^{3}$ Grampo (de cabelo), pregador (de cabelo) e prendedor (de cabelo) não são tratados como unidades fraseológicas do tipo
} colocação por exigirem discussões mais complexas que não cabem neste artigo. 
regional. Também não possuem tal objetivo, por isso formas lexicais típicas da variação regional não constam, em geral, nas obras lexicográficas de uso geral. O que pode ser atestado na consulta dos referidos dicionários.

Assim, com base nos dicionários consultados, verificou-se que, em dois deles, o item lexical misse não se encontra registrado, no entanto, ao buscar pela palavra miss encontrou-se a forma dicionarizada com outras acepções em Aulete (2014) e Houaiss (2015), nas demais obras consultadas, não há verbetes responsáveis pelo significado do referido acessório. As definições encontradas foram:

1. Tratamento formal usado antes do nome de uma mulher solteira e título dado à mulher eleita em concursos de beleza ou em outros eventos.

2. Título dado à mulher eleita em concursos de beleza ou em outros eventos (Miss Brasil); MISSE [com inicial maiúsc. nesta acp.]

3. Moça bonita e elegante; MISSE. (DICIONÁRIO AULETE DIGITAL, 2014, grifo do autor)

Contrariando a acepção encontrada no dicionário, confirmou-se a partir do depoimento que vem ilustrado no exemplo (01), que o informante idoso, da cidade de Euclides da Cunha (BA), compreende o vocábulo misse de acordo com a descrição realizada na questão 192 do questionário semântico-lexical, o que mostra que "os significados não são entidades fixas e perfeitamente determináveis, mas processos flexíveis" (ALMEIDA, 2016, p. 26).

(01) INQ. - E um objeto fino de metal que serve para prender o cabelo?

INF. - Misse.

INQ. - Chama por outro nome?

INF. - Só me lembro de misse. Misse de botar no cabelo.

(Euclides da Cunha-BA, homem, nível fundamental, faixa 2).

No exemplo (02), observa-se que o inquiridor realiza pergunta de desdobramento "E chama aqui por outro nome?" $\mathrm{O}$ informante descreve o objeto e traz uma outra denominação como segunda resposta, diferenciando-o pelo tamanho (Gancho, por exemplo, não foi considerada uma resposta válida, pois, de acordo com a descrição trazida pelo informante, trata-se de outro acessório).

(02) INQ. - E isso aqui para prender os cabelos?

INF. - Isso é misse.

INQ. - E chama aqui por outro nome?

INF. - Não. Chamam de misse mesmo. Porque tem o misse e tem o gancho.

INQ. - E qual é a diferença entre o misse e o gancho?

INF. - Gancho é aquele maior.

INQ. - Sim. E o gancho tem essa coisa assim entortadinha como o misse?

INF. - Não, o gancho as pontas são idênticas iguais a essa, eles botavam assim e fazia assim e saía, coisa e depois prendia.

INQ. - Certo.

(Santo Amaro - BA, homem, ensino fundamental, faixa 2).

\footnotetext{
${ }^{4} \mathrm{O}$ inquiridor realiza perguntas de variadas formas: Conhece de outra forma? Conhece por outro nome? Chama
} de outra maneira? 
Não há verbete para o vocábulo grampo no dicionário de Moraes Silva (1789, 2018). No entanto, esse item lexical se encontra dicionarizado em Ferreira (1999), Aulete (2014) e Houaiss (2015). Além das outras acepções, aparece também como: prendedor de cabelo feito de arame recurvado (FERREIRA, 1999; HOUAISS, 2015).

O dicionário de Aulete (2014, grifo do autor) traz a definição com um exemplo na literatura de Machado de Assis. "Haste metálica dobrada para prender cabelos femininos: '...Iaiá lembrou-se de traçar com um grampo no musgo que reveste o aqueduto, o nome de Jorge...' (Machado de Assis, Iaiá Garcia)".

Tais denominações podem ser exemplificadas no contexto seguinte:

(03) INQ. - E um objeto que as mulheres usam para prender o cabelo?

INF. - Grampo.

INQ. - Só grampo mesmo?

INF. - Conheço como grampo.

(Barra-BA, mulher, ensino fundamental, faixa 1).

Todos os dicionários consultados apresentam acepções para o item lexical presilha. No dicionário de Moraes Silva $(1789,2018)$, há o registro como "a presilha do bocão do chapéo; a qual talvez é de peças de aço, ou pedraria cravada". O dicionário Aulete (2014) descreve como "peça própria para prender o cabelo". Houaiss (2015) apresenta "tira para prender ou afivelar, peça com fecho para prender o cabelo".

No contexto, o informante jovem fala presilha se referindo à pergunta da questão 192, além disso a compara com denominação para o objeto de pesquisa, identifica que as pessoas de outra geração falam o item lexical birilo.

(04) INQ. - E esse objeto aqui que serve para segurar os cabelos? Como se chama esse?

INF. - Eh... uma presilha, né? Tem gente... eh... essas pessoas mais velhas, como meu avô, fala birilo.

INQ. - Seu avô, né? Fala bi...

INF. - Birilo.

INQ. - E... mas você chama como?

INF. - Eu falo presilha, porque prende cabelo quase igual, né?

(Arapiraca - AL, mulher, ensino fundamental, faixa 1).

Assim, como observado no exemplo (04), o item lexical birilo faz parte do vocabulário de muitos informantes. Verificou-se, em todos os dicionários consultados, que a acepção do item lexical birilo ou biliro não foi encontrada, no entanto, ao pesquisar berilo, os quatro dicionários apresentaram outras acepções para este item, como: "um mineral hexagonal, silicato de alumínio e berílio, cujas variedades coloridas podem constituir gemas preciosas (esmeralda, água-marinha etc.)" (AULETE, 2014). É possível observar que a designação berilo como mineral é bem importante. Pode sinalizar para o contexto "pedra de berilo" com a qual se faz/adorna o grampo e em seguida designação do objeto "grampo com os sem adorno" pelo uso da composição com os cristais de berilo. A hipótese ainda precisa ser investigada a fundo e não será explorada neste artigo.

No contexto, os informantes atribuem o léxico birilo às denominações informadas no questionário, como mostra no exemplo (05).

(05) INQ. - E um objeto de metal que prende o cabelo assim?

INF. - Chama ele de Birilo. 
INQ. - Só conhece como birilo mesmo?

INF. - É.

(Salgueiro - PE, homem, ensino fundamental, faixa 1).

A denominação friso somente aparece registrada em Aulete (2014) como grampo de cabelo, além de outras acepções. Nos demais dicionários, encontram-se somente outros significados, "como tornar crespo ou acentuar algo".

1 - Tornar crespo, encrespar.

2 - Ratinar.

3 - Ondear.

4 - Pôr frisos ou frisas em.

5 - Acentuar, tornar saliente. (FERREIRA, 1999).

Moraes Silva $(1789,2018)$ agrega mais uma acepção: “a parte, que está entre o architrave, e a cornija; a qual varía sendo as ordens das columnas".

De acordo com o contexto, tem-se, no exemplo (06), um informante homem de Mossoró (RN), que conhece apenas esse registro na cidade dele.

(06) INQ. - E esse objeto que vamos mostrar?

INF. - Frise.

INQ. - Tem outros nomes?

INF. - Não. Só vejo mais chamar de frise.

INQ. - Ok.

(Mossoró - RN, homem, ensino fundamental, faixa 1).

4.2 Análise geolinguística para "um objeto fino de metal, que serve para prender o cabelo"

Com base no resultado das análises empreendidas no corpus sobre as designações mais frequentes para a pergunta 192: "como se chama um objeto fino de metal, para prender o cabelo?" (COMITE NACIONAL DO PROJETO ALiB, 2001, p. 37), referente à região Nordeste, observa-se que as lexias misse e grampo (de cabelo) concorrem na região de estudo, perfazendo um total de $26 \%, 90$ de 341 dos dados para a lexia misse e $24 \%, 83$ de 341 ocorrências para o item lexical grampo (de cabelo), em seguida, a presilha com $20 \%$, com 67 de 341 dos dados. Verifica-se que, embora os dicionários pesquisados descrevam esse objeto como adorno com fecho, essa lexia vem apresentada de forma frequente na fala dos informantes, referindo-se à questão 192 nas regiões pesquisadas.

O vocábulo birilo/biliro representa $13 \%$ dos dados, ou seja, 46 ocorrências, concentrando-se nas regiões da Paraíba, Pernambuco e Alagoas. Friso concorre com birilo/biliro, perfazendo o total de $13 \%$, o que corresponde à 45 ocorrências. $\mathrm{O}$ item lexical fivela traz o total de $2 \%, 5$ ocorrências e a categorizada como outros, o que se refere às lexias agrupadas: pregador, pegador e cigarra, tem percentual de $2 \%$.

Com base na produtividade de denominações para esse referente, o gráfico 1 traz uma síntese da tabela 1 , levando em conta itens lexicais de maior produtividade na região Nordeste. De forma mais explícita, demonstra visivelmente a predominância da lexia misse, em sequência grampo (de cabelo), presilha também concorre com as duas lexias anteriores, posteriormente temos birilo, friso com o mesmo percentual, fivela possui percentual menor de ocorrência, bem como a categoria outros, que está relacionada à pregador, pegador e cigarra. 
Gráfico 1: Distribuição geral dos dados para "um objeto fino de metal que serve para prender o cabelo" na Região Nordeste com base em dados do Projeto ALiB

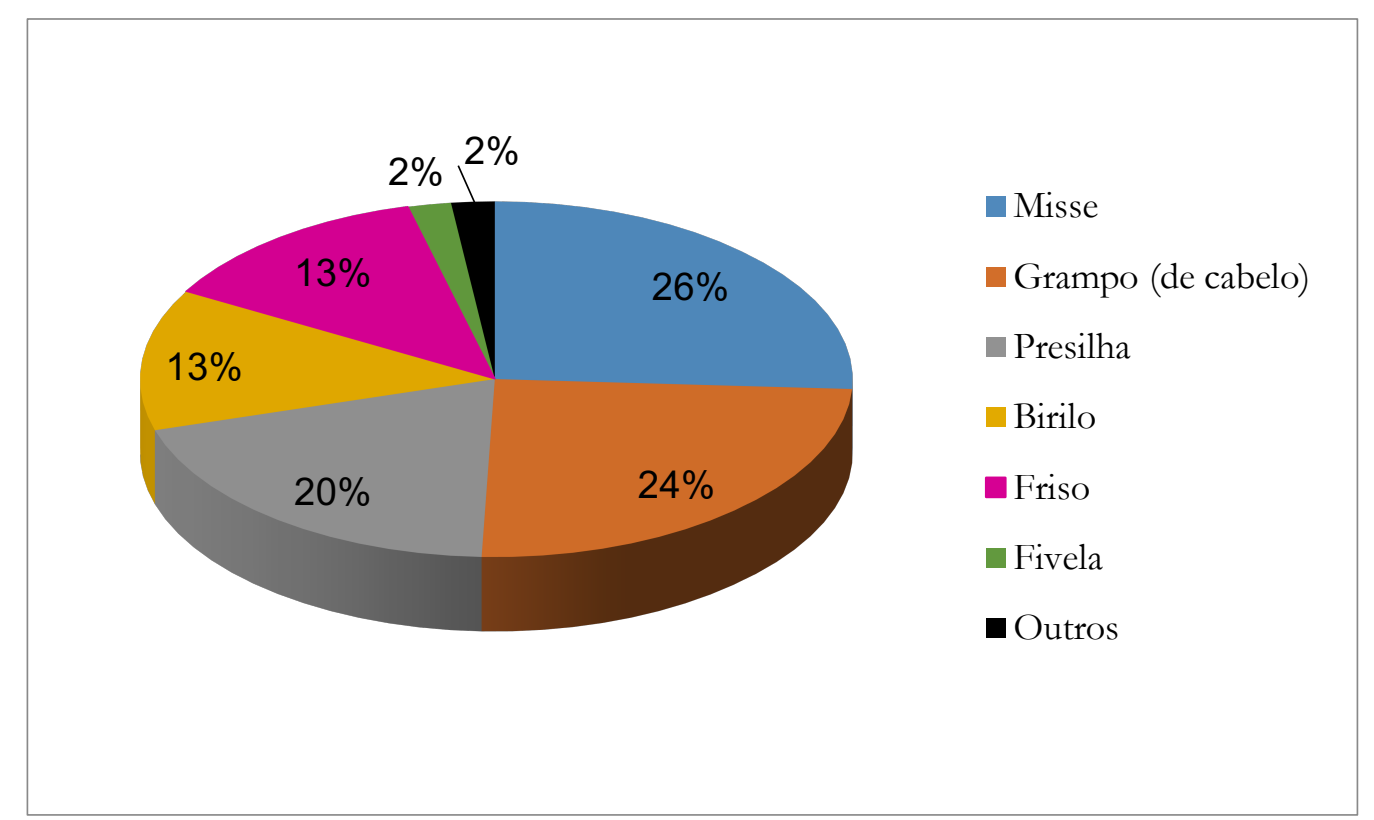

Fonte: autoria própria.

A tabela 1 mostra a produtividade em valor absoluto das variantes para "um objeto fino de metal, para prender o cabelo" na região Nordeste, nela é apresentado o item outros, ou seja, as denominações de pouca ocorrência, como as lexias: cigarra, pegador e pregador.

Tabela 1 - Produtividade das variantes para "um objeto fino de metal, para prender o cabelo" região Nordeste com base em dados do Projeto Atlas Linguístico do Brasil

\begin{tabular}{lccccccc}
\hline & $\begin{array}{c}\text { Misse } \\
\end{array}$ & $\begin{array}{c}\text { Grampo } \\
\text { (de } \\
\text { cabelo) }\end{array}$ & Presilha & Birilo & Friso & Fivela & Outros \\
\hline Maranhão & 0 & 18 & 22 & 0 & 0 & 0 & 0 \\
Piauí & 4 & 8 & 9 & 0 & 0 & 2 & 0 \\
Ceará & 1 & 25 & 23 & 0 & 0 & 2 & 1 \\
Rio G. Norte & 0 & 0 & 0 & 1 & 21 & 0 & 0 \\
Paraíba & 0 & 0 & 1 & 1 & 23 & 1 & 1 \\
Pernambuco & 8 & 3 & 0 & 37 & 1 & 0 & 3 \\
Alagoas & 0 & 4 & 9 & 35 & 0 & 0 & 0 \\
Sergipe & 14 & 2 & 0 & 0 & 0 & 0 & 0 \\
Bahia & 63 & 23 & 3 & 0 & 0 & 0 & 0 \\
Total & 90 & 83 & 67 & 46 & 45 & 5 & 5 \\
\hline Fona: & & & & & & & \\
\hline
\end{tabular}

Fonte: autoria própria. 
É importante mencionar que se percebe a variação por conta da diferença em número de localidades. O item lexical misse possui maior frequência na Bahia e em Sergipe. O segundo com maior produtividade, grampo (de cabelo), é utilizado por informantes da Bahia, de Sergipe, de Alagoas, quase todo Estado do Ceará e do Maranhão e no Piauí. O item presilha está nas cidades do Rio Grande do Norte e de Alagoas e em algumas localidades do Ceará. Birilo aparece nos municípios de Pernambuco e Alagoas e friso é preponderante no Rio Grande do Norte e na Paraíba.

Essa fotografia diatópica pode ser visualizada na cartografia experimental I.

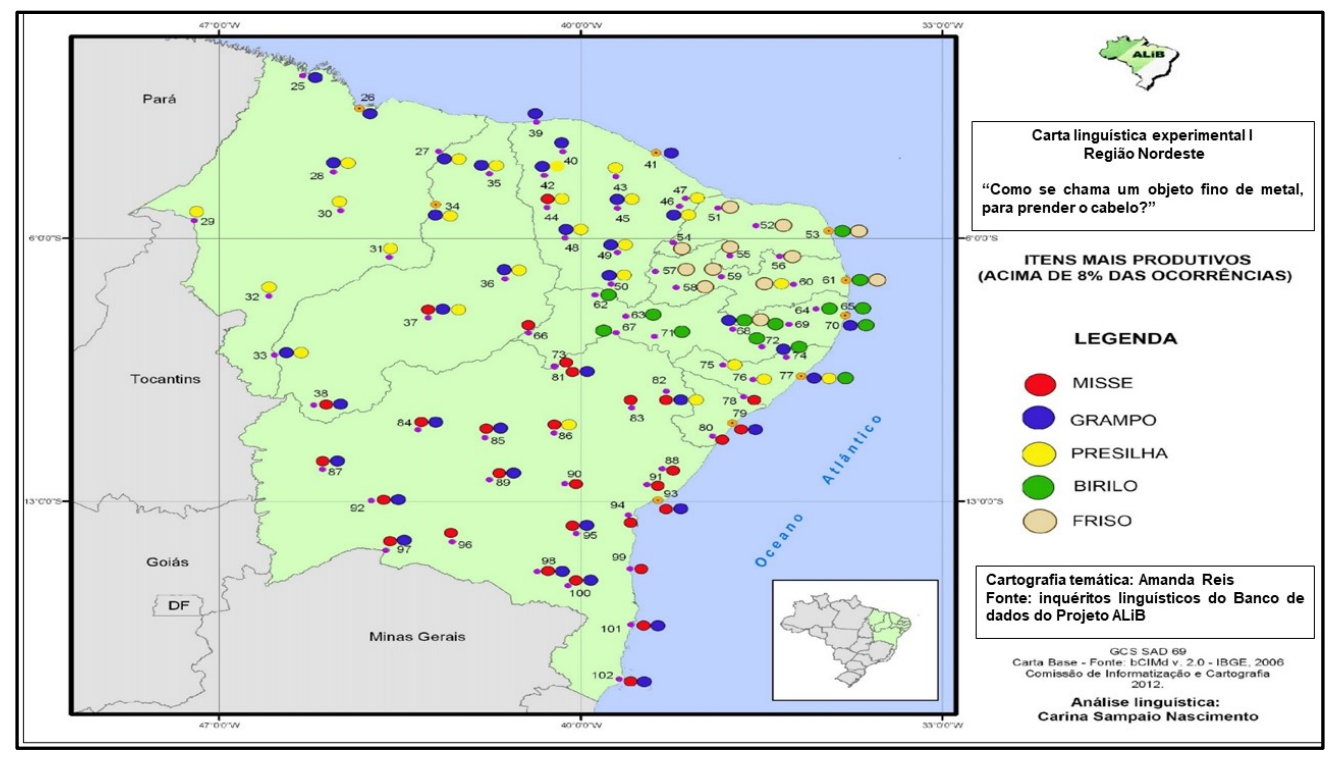

O gráfico 2, que segue e revelará os dados da região Sul, demonstra visivelmente a predominância da lexia grampo (de cabelo) na área geográfica estudada, na sequência, verifica-se a distribuição do item lexical ramona, posteriormente temos prendedor (de cabelo), pregador (de cabelo), joaninha, ladona, passador e presilha.

Gráfico 2: Distribuição geral dos dados para "o objeto fino de metal que serve para prender o cabelo" na região Sul com base em dados do Projeto ALiB

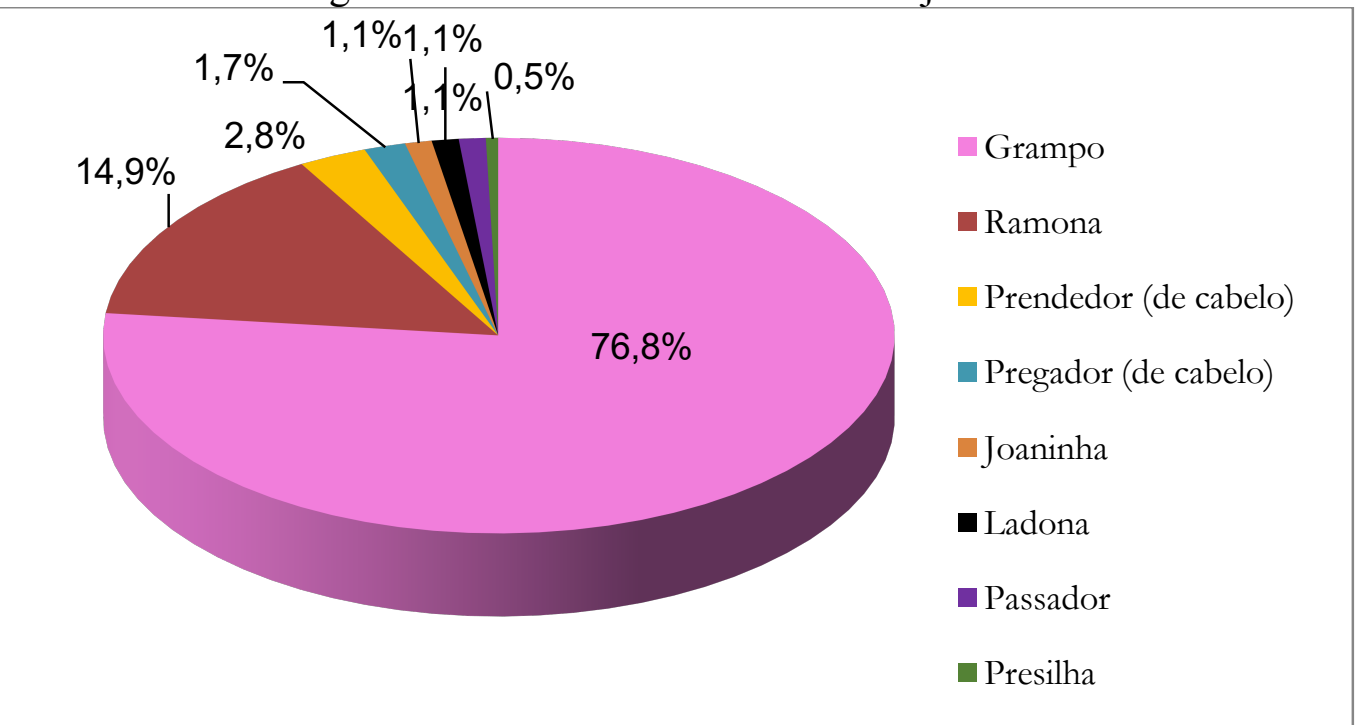

Fonte: autoria própria. 
A tabela 2 mostra o detalhamento dos dados em relação às localidades da região Sul das variantes para "um objeto fino de metal, para prender o cabelo".

Tabela 2 - Produtividade das variantes para "um objeto fino de metal, para prender o cabelo" na região Sul com base em dados do Projeto Atlas Linguístico do Brasil

\begin{tabular}{lcccccccc}
\hline & Grampo & Ramona & $\begin{array}{c}\text { Prendedor } \\
\text { (de cabelo) }\end{array}$ & $\begin{array}{c}\text { Pregador } \\
\text { (de cabelo) }\end{array}$ & Joaninha & Ladona & Passador & Presilha \\
\hline Paraná & 44 & 20 & 4 & 1 & 0 & 0 & & 1 \\
$\begin{array}{l}\text { Santa } \\
\text { Catarina }\end{array}$ & 38 & 3 & 1 & 1 & 0 & 0 & & 0 \\
$\begin{array}{l}\text { Rio } \\
\text { Grande } \\
\text { do Sul }\end{array}$ & 57 & 4 & 0 & 1 & 2 & 2 & 2 & 0 \\
Total & 139 & 27 & 5 & 3 & 2 & 2 & & 1 \\
\hline
\end{tabular}

Fonte: autoria própria.

Com base na tabela 2, podemos verificar, a partir da comparação entre os dados das duas regiões, que somente duas designações são comuns: grampo e presilha, no entanto apenas grampo possui mais produtividade nas duas regiões. Na região Sul, o item presilha aparece no Paraná. Ele é comum nas duas regiões, no entanto na região Sul possui apenas uma ocorrência

Em relação à carta experimental II, que segue, podemos perceber a distribuição espacial dos itens lexicais coletados na região Sul para designar o referente pesquisado, na qual mostra maior produtividade dos léxicos grampo e ramona no Paraná, Santa Catarina e Rio Grande do Sul.

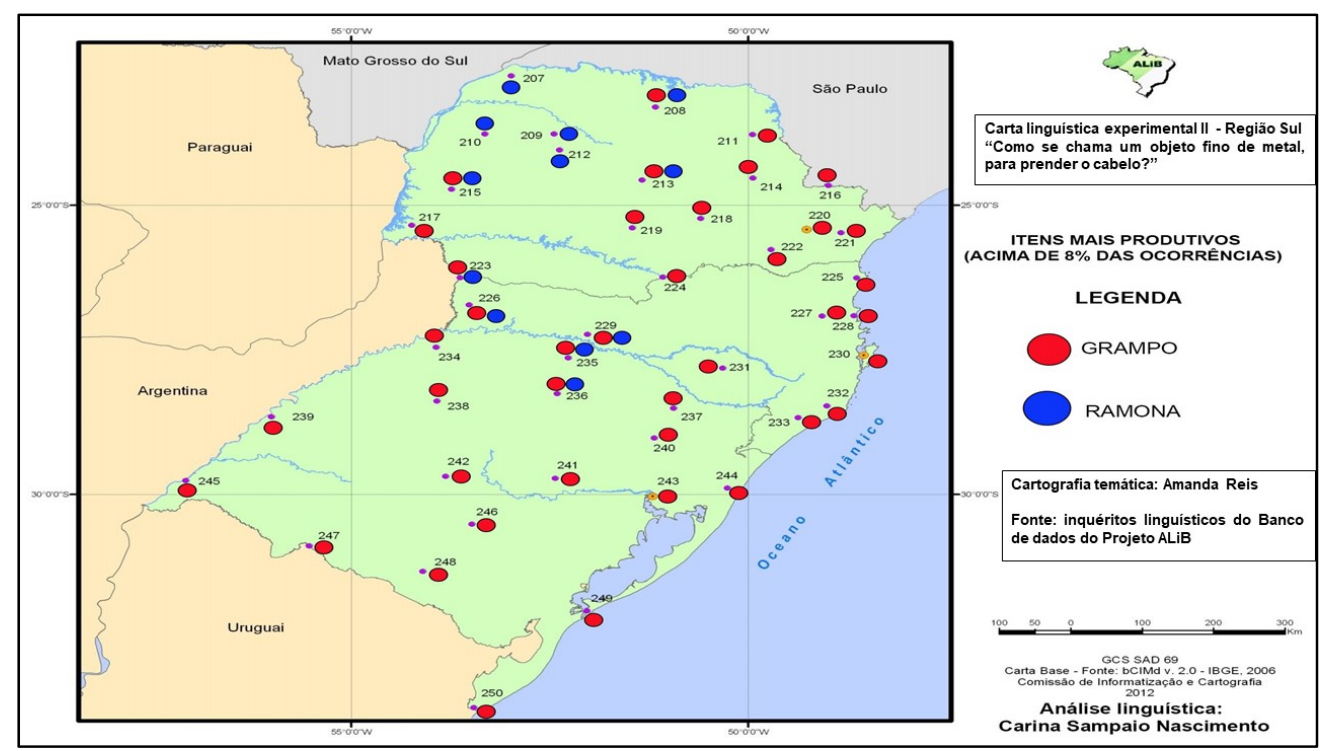

A carta experimental II demonstra visivelmente a predominância da lexia grampo (de cabelo) em quase todas as localidades estudadas na região Sul, exceto nas cidades Nova Londrina, Terra Boa, Umuarama e Campo Mourão, pontos 207, 209, 210 e 212, respectivamente, pertencentes ao Estado do Paraná.

Em sequência, verifica-se a distribuição do item lexical ramona em algumas localidades do Paraná, como: Nova Londrina, Londrina, Terra Boa, Umuarama, Campo Mourão, Cândido de Abreu, Toledo e Barracão, pontos 207, 208, 209, 210, 212, 213, 215 e 223; no Estado de Santa Catarina, em São Miguel do Oeste e Concórdia, pontos 226 e 
229; por fim, no Estado do Rio Grande do Sul, em Erechim e Passo Fundo, pontos 235 e 236.

\section{Considerações finais}

O estudo realizado demonstrou uma significativa diversidade de designações para um objeto fino de metal, para prender o cabelo nas regiões Nordeste e Sul do Brasil, tendo - grampo (de cabelo) - como item lexical presente nas duas regiões de forma predominante. No Nordeste, as lexias fivela, pregador (de cabelo), pegador (de cabelo) e cigarra tiveram menor ocorrências; já no Sul, as formas lexicais de menor ocorrência foram prendedor (de cabelo), pregador (de cabelo), joaninha, ladona e presilha. Isso mostra que essas denominações confirmam o caráter dinâmico da língua, em que novas formas vão surgindo e outras vão desaparecendo.

No que diz respeito às denominações que recebem a pergunta 192 do questionário semântico-lexical referente ao campo dos acessórios, podem-se fazer algumas considerações preliminares:

a) a pesquisa dos itens lexicais nos dicionários é de grande relevância, pois estes servem de instrumentos que possuem informações necessárias para o estudo da palavra;

b) as denominações encontradas como resposta para a questão 192 apresentam uma diversidade lexical e geolinguística do português falado no Brasil;

c) as variantes lexicais de maior produtividade no Nordeste foram: misse; grampo (de cabelo); presilha; birilo; friso;

d) as variantes lexicais de maior produtividade na região Sul foram: grampo; ramona;

e) o léxico presilha é comum nas duas regiões, no entanto na região Sul possui apenas uma ocorrência.

Os resultados do estudo têm apontado para a importância de se investigar o léxico com base em dados orais, de natureza geolinguística, por serem fontes espontâneas e produtivas, demonstrando a verificação de uma realidade espacial e podendo apontar diferenças e semelhanças nas regiões brasileiras.

\section{REFERÊNCIAS}

ALMEIDA, A. Ariadne Domingues. Histórias sobre as redes de significação do item léxico foda à luz do sociocognitivismo. In: ALMEIDA, A. Ariadne Domingues; SANTOS, Elisângela Santana dos. (org.). Linguagens e cognição. Salvador: EDUFBA, 2016.

Atlas Linguístico-Etnográfico de Portugal e da Galiza (ALEPG), Disponível em: http://www.clul.ulisboa.pt/pt/23-investigacao/681-alepg-atlas-linguistico-etnograficodeportugal-e-da-galiza. Acesso em: 26 de jan. de 2018.

COMITÊ NACIONAL DO PROJETO ALiB. Atlas Linguístico do Brasil. Questionários. Londrina: Editora da UEL, 2001.

COSERIU, Eugenio. Sentidos e Tareas de la Dialectologia. México: Instituto de Investigaciones filológicas - Centro de Lingüística Hispánica, 1982.

COSGRAVE, Bronwyn. História da Indumentária e da Moda: da antiguidade aos dias atuais. Trad. Ana Resende. Barcelona: Editorial Gustavo Gili, 2012.

DICIONÁRIO AULETE DIGITAL. 2014. Disponível em: $<$ http://www.aulete.com.br/site.php?mdl=aulete_digital $>$. Acesso em: 26 de jan. de 2018. 
FERREIRA, A. B. de H. Novo Aurélio Século XXI: o dicionário da língua portuguesa. 3. ed. Rio de janeiro: Nova Fronteira. 1999.

HOUAISS, Antônio. Dicionário Houaiss da Língua Portuguesa. São Paulo: Moderna, 2015.

LAVER, James. A Roupa e a Moda: uma história concisa. Trad. Glória Maria de Mello Carvalho. São Paulo: Companhia das Letras, 1989.

LIMA, at al. Grampo para cabelo: da invisibilidade à transformação em objeto de moda. $12^{\mathrm{o}}$ Colóquio de Moda $-9^{\mathrm{a}}$ Edição Internacional, 2016. Disponível em: http://www.coloquiomoda.com.br/anais/Coloquio\%20de\%20Moda\%20\%202016/COMUNICACAO-ORAL/CO-05-Marketing/CO-05-Grampo-para-cabeloda-invisibilidade-a-transformacao-em-objeto-de-moda.pdf. Acesso em: 02 nov. 2018. LIPOVETSKY, Gilles. O império do efêmero. São Paulo: Companhia das Letras, 2009. MORAES SILVA, Antonio de. Dicionário da Língua Portugueza. Lisboa, 1789. Disponível em: http://dicionarios.bbm.usp.br/pt-br/dicionario/ Acesso em: 10 dez. 2018.

Recebido em: junho de 2020. Aprovado em: setembro de 2020.

Como citar este trabalho:

NASCIMENTO, C. S.; PAIM, M. M. T. A variação lexical no campo semântico dos acessórios do Projeto Atlas Linguístico do Brasil. Traços de Linguagem, v. 4, n. 1, p. 24-37, 2020. 